\title{
Effect of anthraquinone on alkaline pretreatment and enzymatic kinetics of sugarcane bagasse saccharification: Laboratory and Pilot Scale approach
}

Nascimento, V. M¹, Nakanishi, S. C., ${ }^{1,2}$ Rocha, G. J.M¹ *., Rabelo, S. C' ${ }^{1}$, Pimenta, M. T.B., Rossell, C. E. $\mathrm{V}^{1}$.

${ }^{1}$ Laboratório Nacional de Ciência e Tecnologia do Bioetanol (CTBE), Centro Nacional de Pesquisa em Energia e Materiais (CNPEM), Caixa Postal 6192, Rua Giuseppe Máximo Scolfaro, 10.000, CEP 13083-970, Campinas, São Paulo, Brasil.

${ }^{2}$ Departamento de Biotecnologia, Escola de Engenharia de Lorena- USP Estrada Municipal do Campinho, s/n - Pte. Nova, Lorena - SP, CEP: 12602-810, Lorena, SP. Brasil.

* Corresponding author: george@debiq.eel.usp.br

\section{Content}

Table S1 - Scaled regression coefficients of the regression model of cellulose solubilization from sodium hydroxide pretreatment with anthraquinone. S2

Figure SI - Enzymatic conversion of cellulose versus time for samples pretreated in pilot scale with and without anthraquinone addition.

Figure SII - Linear correlation expressed as a Langmuir equation $[\mathrm{t} / \mathrm{EC}=1 / \mathrm{ab}+\mathrm{t} / \mathrm{a}]$, being: "t", the hydrolysis time in hours, "EC", the cellulose conversion and "a" is a factor related to the capacity for the enzymatic hydrolysis of cellulose. ${ }^{[45]}$ S3 
Table S1 shows the scaled regression coefficients of the regression model of cellulose solubilization after sodium hydroxide with anthraquinone pretreatment. The statistical analysis was performed using the software Statistica (Statsoft, v. 10.0) and the confidence level considered was 90\%. Significant effects are marked in bold ( $\mathrm{p}$ value < $0.1)$.

Table S1 - Scaled regression coefficients of the regression model of cellulose solubilization from sodium hydroxide pretreatment with anthraquinone.

\begin{tabular}{|c|c|c|c|c|c|c|}
\hline \multirow[b]{2}{*}{$\begin{array}{c}\text { Factor } \\
\text { average }\end{array}$} & \multicolumn{2}{|c|}{$\begin{array}{c}\text { Cellulose } \\
\text { solubilization }\end{array}$} & \multicolumn{2}{|c|}{$\begin{array}{l}\text { Hemicellulose } \\
\text { solubilization }\end{array}$} & \multicolumn{2}{|c|}{$\begin{array}{c}\text { Lignin } \\
\text { solubilization }\end{array}$} \\
\hline & $\begin{array}{l}\text { Coeficient } \\
\mathbf{1 6 . 8 3 2 0 1}\end{array}$ & $\begin{array}{l}\text { p- valor } \\
\text { 0.00071 }\end{array}$ & $\begin{array}{c}\text { Coeficient } \\
\mathbf{3 8 . 3 4 4 1 8}\end{array}$ & $\begin{array}{l}\text { p- valor } \\
\text { 0.00018 }\end{array}$ & $\begin{array}{c}\text { Coeficient } \\
\mathbf{5 4 . 0 1 0 3 2}\end{array}$ & $\begin{array}{l}\text { p- valor } \\
\text { 0.00001 }\end{array}$ \\
\hline Time (1) & 0.65492 & 0.34014 & 0.33196 & 0.64107 & -0.92594 & 0.04230 \\
\hline $\begin{array}{l}\text { Temperature } \\
\text { (2) }\end{array}$ & 1.31865 & 0.12956 & 7.50465 & 0.00655 & 7.20877 & 0.00074 \\
\hline $\mathrm{NaOH}(3)$ & 4.48831 & 0.01353 & 8.55257 & 0.00506 & 25.57099 & 0.00006 \\
\hline $1 * 2$ & 2.97974 & 0.02992 & 2.83689 & 0.04331 & 1.58660 & 0.01503 \\
\hline $1 * 3$ & 1.89529 & 0.06945 & 0.55765 & 0.45736 & -1.71609 & 0.01289 \\
\hline $2 * 3$ & -2.17724 & 0.05396 & -3.76097 & 0.02534 & -3.42793 & 0.00328 \\
\hline $1 * 2 * 3$ & -1.7165 & 0.08283 & -1.88711 & 0.09062 & -1.50683 & 0.01662 \\
\hline
\end{tabular}




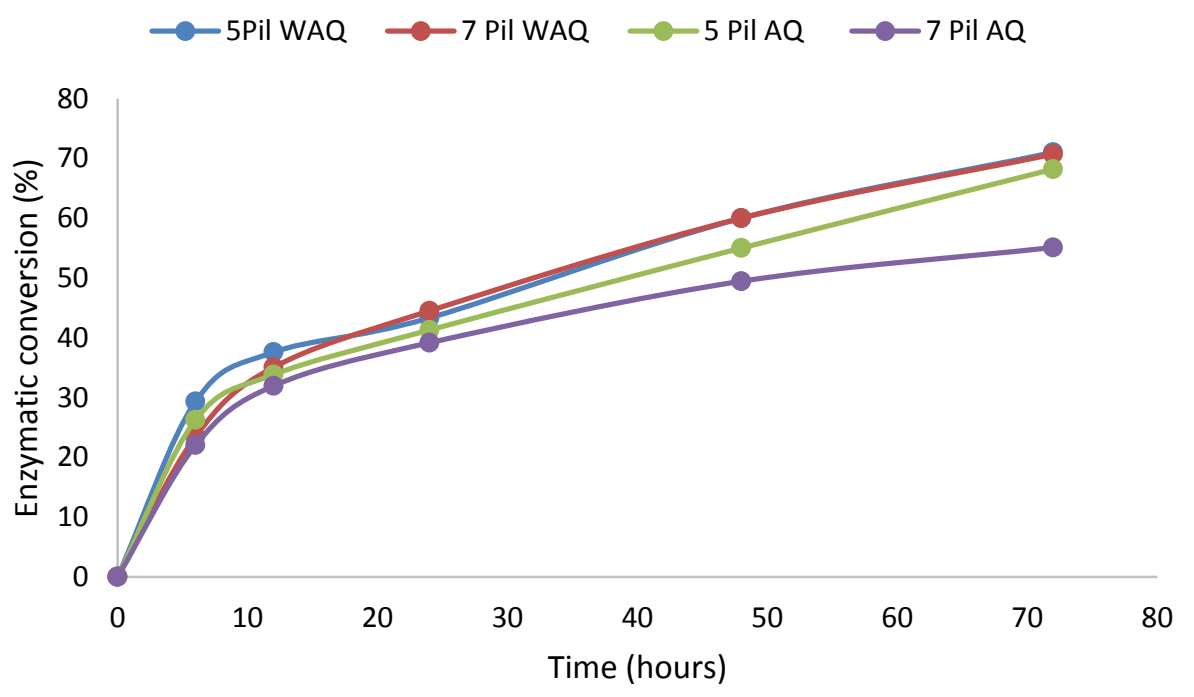

Figure SI - Enzymatic conversion of cellulose versus time for samples pretreated in pilot scale with and without anthraquinone addition.

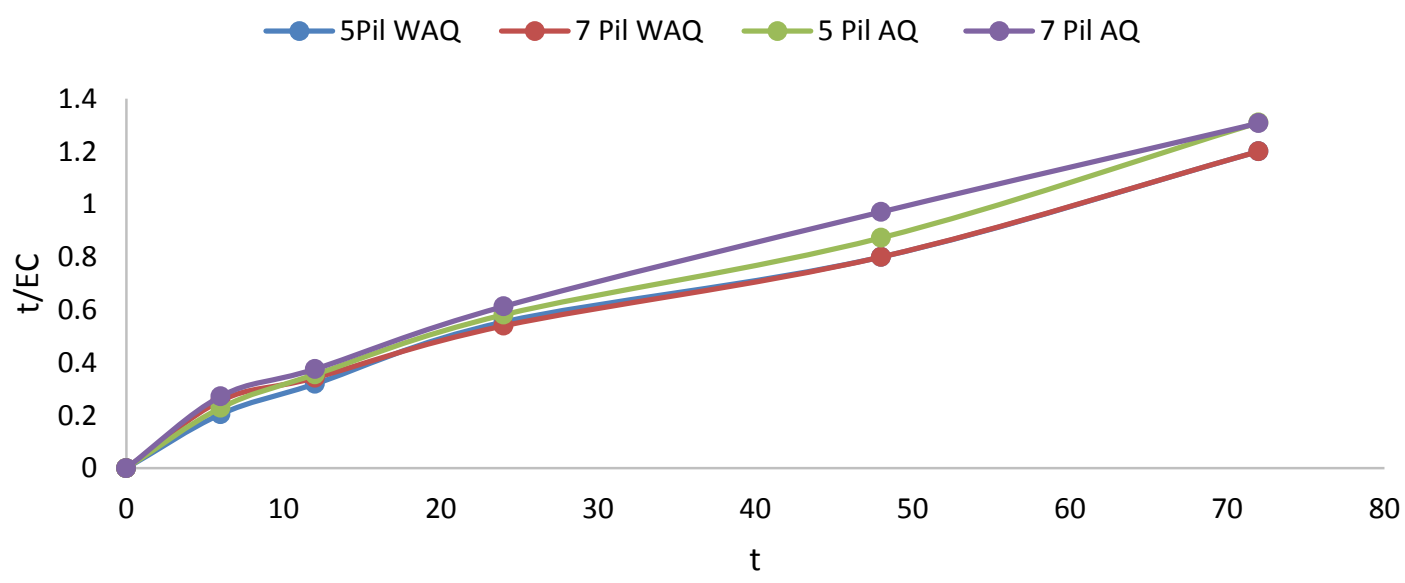

Figure SII - Linear correlation expressed as a Langmuir equation $[\mathrm{t} / \mathrm{EC}=1 / \mathrm{ab}+\mathrm{t} / \mathrm{a}]$, being: " $t$ ", the hydrolysis time in hours, "EC", the cellulose conversion and "a" is a factor related to the capacity for the enzymatic hydrolysis of cellulose. ${ }^{[45]}$ 